Studia UBB 婿igitalia, Volume 63 (LXIII) 2018, December, Issue 2, 31-49

Published Online: 2018-12-30

DOI:10.24193/subbdigitalia.2018.2.03

\title{
Romans 1by1. A Database Manual
}

\author{
Rada Varga, Annamária-Izabella Pázsint, Angela Lumezeanu \\ Babeș-Bolyai University
}

\begin{abstract}
The present paper has the goal to document the usage of the Romans 1by1, a database which records the people attested in the epigraphic sources coming from the Roman provinces; so far, we have registered Dacia, Moesia Inferior and Moesia Superior in full and are currently working on the epigraphy of Pannonia. The information started to be collected in 2015, and it is still in progress, the intention being to extend the geographical area as much as possible. The database represents an extremely useful resource in the study of ancient population, as well as a very user- friendly research tool, which allows primary browsing and selective, advanced searches alike.
\end{abstract}

Keywords: database, guidebook, Latin epigraphy, population database, database architecture

\section{Introduction \& Structure}

The database has two components, one which is designed for account-based users, respectively to the researchers who are continuously building the database, and another one, which is an open access database designed for public use. The architecture, principles and functioning mechanisms of the first one have been partially documented (Varga, "Documenting"; Varga, "New Developments"; Varga et al.; Varga and Lumezeanu), but in the following lines we will address both platforms in order to provide a guide for the user.

After the introduction we will present a short overview of the historiography of the research, followed by the documentation of the central database and by the brief presentation of the dissemination (open access) database, concluding with some of the differences between the two of them. 


\section{Historiography of the research}

Databases have started to be used in the humanistic field in the last decades, being applied in various research projects from a variety of sub-fields, from history, to linguistics, geography, demography, etc. As such, a need to document them has emerged, producing as a result a wide variety of database manuals. For historical demography, the article of Mademakers and Dillon is a point of reference, since it provides a list of "best practices for the creation of large databases on historical populations" (34). Other articles document various databases, or present some of their major contribution and use, as such we mention the ifo Prussian Economic History Database - iPEHD (Becker et al.), the spatial database for medieval fiscal data in Southern Italy (Carrion et al.), or the North Atlantic Population Project (Rugglers et al.), etc. Specific research questions and the use of specific methodologies have been also at the core of some articles, such as the one of Hedefalk, Harrie and Svensson whom developed "a methodology to create databases that can be used to add micro-level geographic context to longitudinal historical demographic analyses" (153). Huistra and Mellink on the other side focused on the search technologies which are better designed for "historical source selection in digital repositories" (220), while Massey assessed the accuracy in linked historical data, etc.

\section{The central database:}

The first and foremost step that the user needs to take is to become familiar with the source, which implies the reading of the inscription and its translation, as well as of all the other details regarding it. As such, the first edition of the inscription should be used, as well as any newer editions which bring significant contributions to its reading or interpretation (Fig. 1).

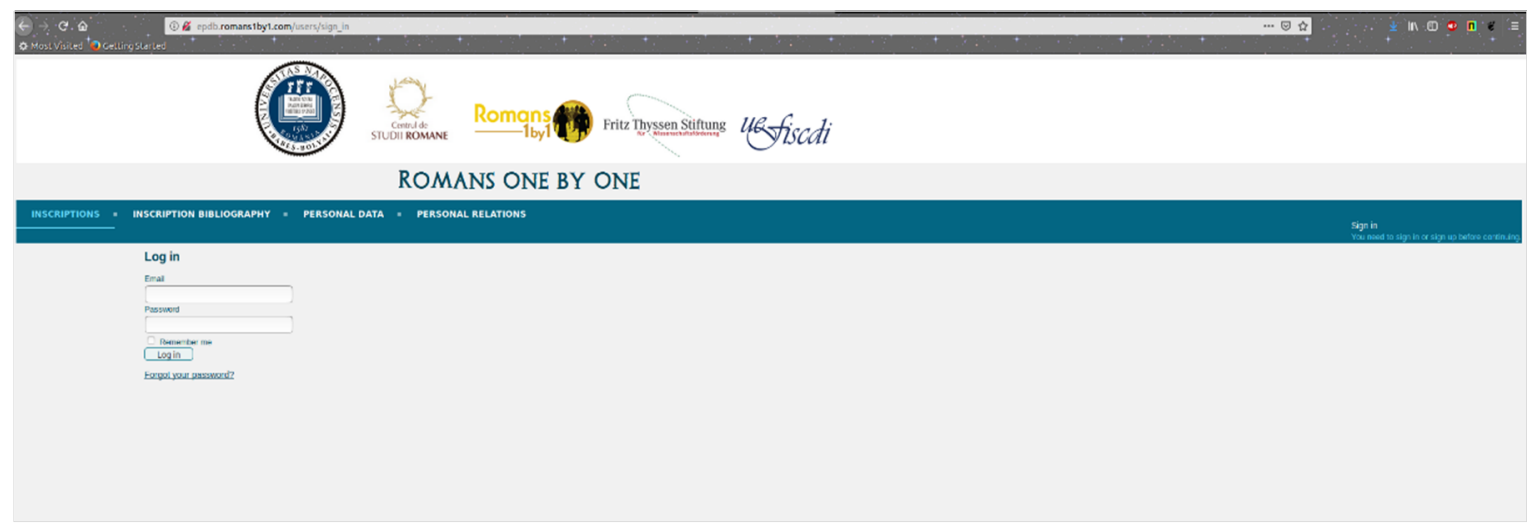

Fig. 1. Log-in inferface of the database 
The database has four main tables (inscriptions, inscription bibliography, personal data, personal relations) and each of their corresponding record sheet have three main types of fields:

1) fill-in box, in which the author introduces the information (the comments are in English, but the other information is recorded in the language of the source);

2) drop-down menu, from which the user only selects the information;

3) check-in box, where the user makes a decision between two opposite choices (yes/no). The selected state opens sometimes new data sets.

\section{Inscriptions}

The first step in creating an entry is generating a new inscription record, more precisely, the author presses the button New inscription record and creates a new file (Fig. 2). The author gives to the chosen inscription a code of five digits (i.e. 00001) ending with an acronym representing the abbreviation of the province's name (MI for Moesia Inferior, MS for Moesia Superior, DP for Dacia Porolissensis, DI for Dacia Inferior, DS for Dacia Superior, PI for Pannonia Inferior, PS for Pannonia Superior) (i.e. 00001 MI).

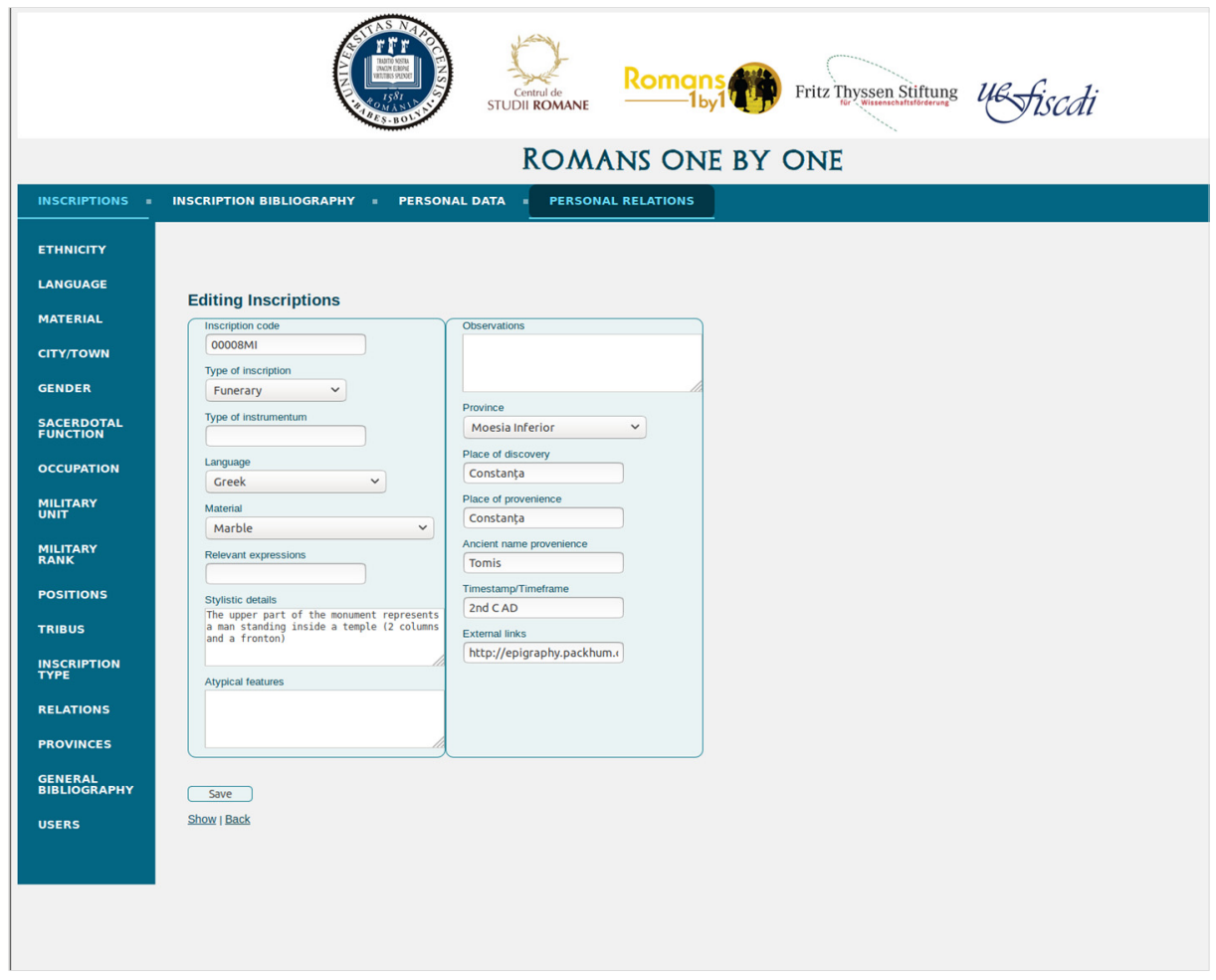

Fig. 2. New inscription file 
Next, from a drop-down menu the operator selects the Type of inscription (funerary, votive, etc.), followed by filling in Type of instrumentum (ring, tile, etc.) if appropriate. From different drop-down menus, the Language (Greek, Latin, etc.) of the inscription is chosen, and the Material (marble, sandstone, gold, etc.) from which the monument was made. These are followed by four textboxes which are to be filled in if the information exists: Relevant expressions (ex viso libenter, aedem vetustate conlapsam - sic!, etc.), Stylistic details (pulvini, marble stele with pediment and acroterion, etc.), Atypical features (on a column, written DD MM, etc.), and Observations (any additional information on the source which the author of the record considers relevant and which do not fit any of the other fields).

Continuing, a drop-down menu allows the user to select the Province (Pannonia Inferior, Moesia Superior) from where the inscription comes, and then five other text fields are to be filled in: Place of discovery (Orăștie, Lyon, etc.), Place of provenience (Sarmizegetusa, Lugdunum, etc.), Ancient name of provenience (Sarmizegetusa, Lugdunum, etc.), Timestamp/ timeframe $\left(2^{\text {nd }}-3^{\text {rd }} c . A D, 101-107 A D\right.$, etc.) and External links. In what concerns the external links textbox it is filled in with links from the EDH (https://edh-www.adw.uni-heidelberg.de/home) and PHI (https://epigraphy. packhum.org/) databases. The final step is to click the Save button. Once this has been done, the inscription record is created and the next step can be taken.

\section{Inscription bibliography}

After recording the inscription, the following step is to create a bibliographic file. The author presses the button New bibliography inscription in order to create a new entry (Fig. 3). At this stage, from a drop-down menu the previously recorded inscription code is selected and then again, from a drop-down menu, the Bibliography abbreviation (CIL, AE, etc.) is also selected. The table General Bibliography contains the complete bibliographical list, with all the titles referred to in the database and their corresponding abbreviations and the drop-down list is referenced to it. 


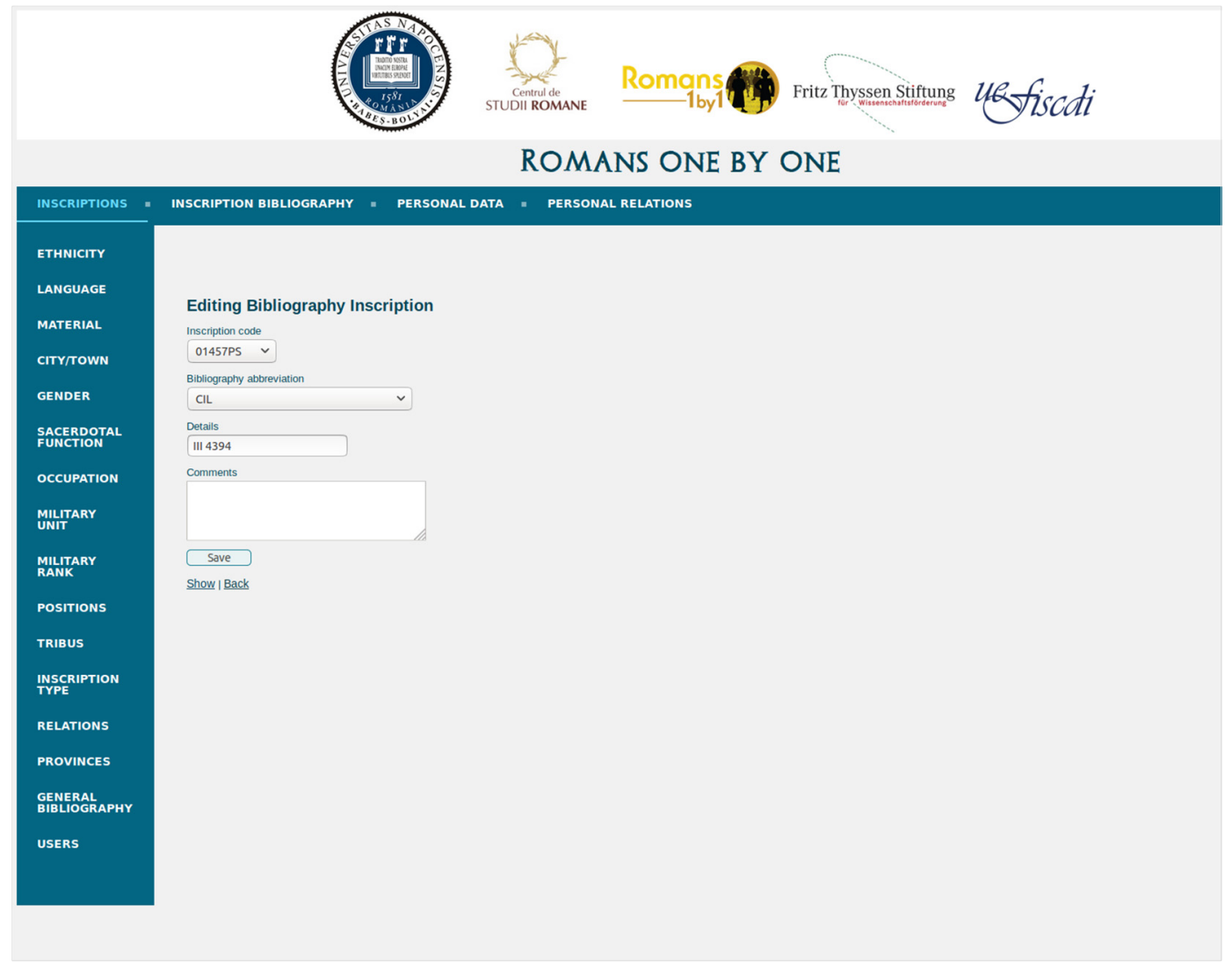

Fig. 3. New bibliography file

The text field Details (III 789; 1997, 1234, etc.) is destined to comprise the number of an inscription from an epigraphic corpus, or the page and the number under which an inscription was published. The Comments section gives the author of the record the possibility to insert any additional information regarding the publication. These fields are supposed to provide detailed bibliographic information related to the inscription. Considering the fact that most of the inscriptions have benefitted from various editions, several Bibliography inscription entries can be attached to an inscription code.

\section{Personal data}

The third and most important table is the Personal data, recording the prosopographic information. As such, the author passes to the personal data tab and clicks New person data (Fig. 4). This leads the user to a complex standardized informational sheet which allows oneself to fill-in/ select several types of information given they are provided by the source, of course. Each recorded individual will be 
automatically assigned a unique identifier, which is also comprised in the personal URI (e.g. http://romans1by1.com/rpeople/32).

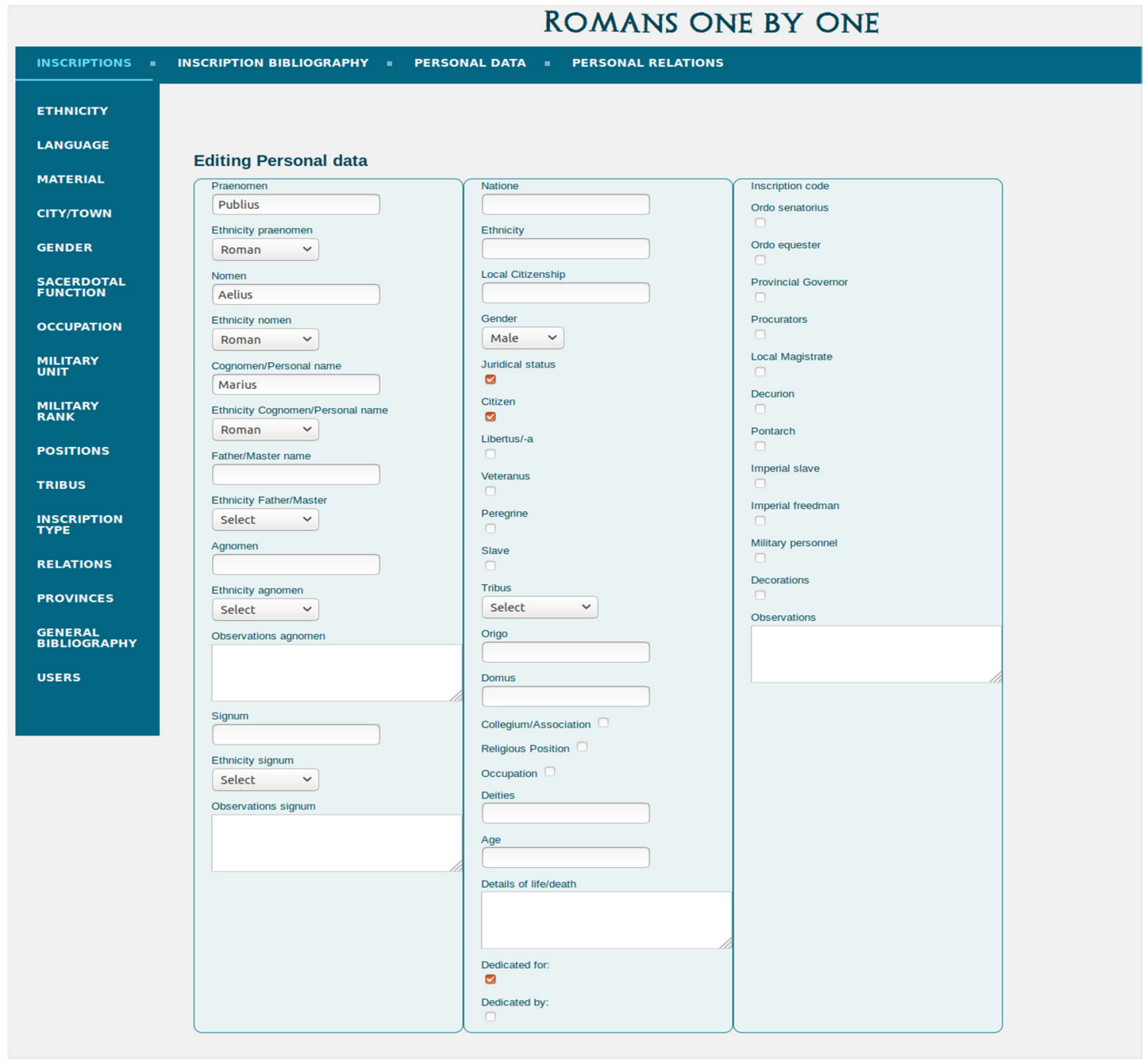

Fig. 4. New person file

The sheet contains onomastic data, information related to the juridical status of the individuals, their ethnic and geographical provenience, social and religious background, professional status, cursus honorum, as well as other details of their life, such as the age, life events, or information regarding the person whom elevated the monument. In the following lines we will address each section and provide further details on the recording procedure. 
The first section is Onomastic data; in this part there are fill-in boxes, followed by drop-down menus, each of the latter allowing the user to select the ethnicity corresponding to the name components. As such, from this onomastic category we have the following individual textboxes: Praenomen (Marcus, Caius, etc.), Nomen (Aurelius, Vireius, etc.), Cognomen/ Personal name (Regulus, Lucilianus, etc.), Father/ Master name (Zoticus, Titus, etc.), Agnomen (e.g. Passer; this category has also an Observations box attached), and Signum (as well, this category has also an Observations box; very scarce, we haven't registered any certain signum so far).

This being a standardized sheet, it means that not all of the information always appears on the inscriptions, as such, several particularities are to be mentioned. Obviously, in the case when an individual certainly did not have a tria nomina or a duo nomina, the textboxes are to be left empty, but, in the case when one of the component of the tria or duo nomina is not readable due to the physical condition of the monument, then the box should be filled in with the sign [---]. In case the personal name of an individual is missing, but the existence of a person is deduced from the text, the author may insert in the cognomen/ personal name box either the word 'such' which is generally used in the literature when the name of an individual is missing, or the sign [---]. The latter is to be used especially in the cases when we have other onomastic details, such as the praenomen or the nomen of an individual. In general, for the Greek names we have opted to use, in these cases, the word "such", while when there were attested tria or duo nomina we have opted to use the sign [---].

In the cases where one of the components of the tria or duo nomina, or of the personal name is fragmentary, then the user is to insert in the textbox the letters, which are readable on the inscription. For example, if on the inscription we read only the ending of one's personal name "-ẃpos", then the user will fill-in the box as follows: [---]ẃpos (ID 463), showing that only the final letters are known to us.

It must be noted that for this phase of the project, in which we have not targeted to go deeply into onomastic analyses and details, the ethnicity of the name remains available only upon login and they have not been transferred to the open access database. From a linguistic point of view, the names recorded in the boxes are to be written in the Nominative case, no matter in which case it appears on the inscription. The Greek names are not to be transliterated into the Latin alphabet, as the intent is to render faithfully the evidence from the source of information.

After the onomastic section, the following is focused on the Juridical status, Ethnic and Geographical origin of the individual. As such, we have the box Natione, in which we can mention the nation of the individual if it appears on the monument explicitly 
(e.g. natione Thracus), followed by the box Ethnicity, in which we mention the ethnicity if it appears on the monument (e.g. Thracus). To clarify matters, in this section we are referring to ethnical origins explicitly stated as such on the monument, not to the inferred ethnical and geographical provenience of the name which we mentioned above. Subsequently, we have a local citizenship box in which we can introduce details about the local juridical status of an individual. This box was very useful in the case of the Greek cities from Moesia Inferior, where some of the individuals might not have been Roman citizens (previous to AD 212) but had the local citizenship. In some cases, the

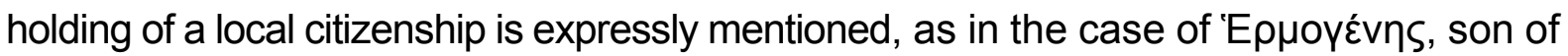
ignotus (ID 46) who was a citizen of Ancyra and Tomis, but in other cases the information is inferred. The juridical status can be inferred by at least three types of evidence: the

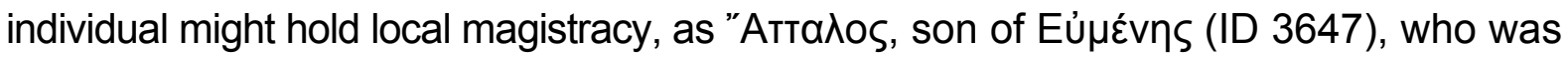

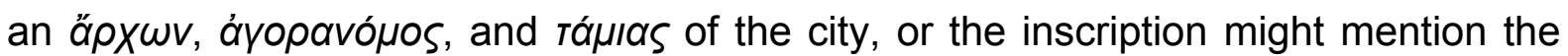

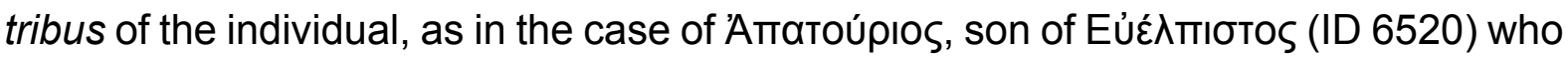

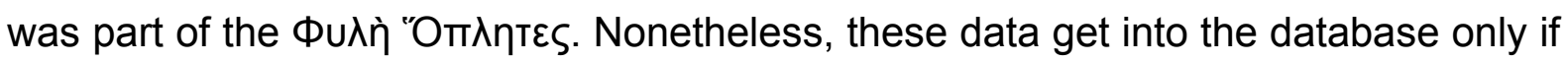
they are un-doubtable.

The Gender drop-down menu allows to select among three options: female, male, and unknown. Since there are many fragmentary inscriptions which do not allow to render with certitude the gender of the individual, the unknown category is extremely important, and records (for the moment) 667 such cases.

Next, the user must deal with the Juridical status by ticking this category, which opens a series of boxes which must be ticked as well: Citizen, Libertus/-a, Veteranus, Peregrine, Slave. Among these, if ticked, the Veteranus box opens other options: from a drop-down menu one can select, if known, the Veteranus unit (legio $V$ Macedonica, cohors I Vindelicorum, etc.) and the Veteranus rank (centurio, beneficiarius, etc.) of the individual.

Next the author has the possibility to select from a drop-down menu the name of the Tribus to which an individual was part of.

Then, follow the Origo and Domus fill-in boxes, which are to be filled in if the source mentions these types of information. Namely, origo stands for the place of provenience, which can be a province, an area or a city (Lugdunum, regione Laodicea, etc.) and domus, when recorded explicitly, indicates the town or community of provenience (Verona, Emona, etc.)

Next comes the Collegium/ association tick-box, which if ticked opens a series of fill-in boxes: Type of association (religious, professional), Position (magister, agonothetes, etc.) within the association and Activities within the association. 
The Religious position check-box resembles the previous one and if checked opens a variety of possibilities. The author can choose from a drop-down list the Sacerdotal office of an individual (antistes, augur, flamen, haruspex, pontifex), or they can check the box Coloniae/ municipii sacerdos, Military sacerdos, Imperial priest, Divinity priest, Laurentium Lavinatium, each of which if checked open a details box for the author to add any supplementary information.

The Occupation check-box follows, which if checked opens a drop-down list with a multitude of encoded occupation titles (Varga, "Professionals" 9-22), which can be selected if appropriate (negotiator, pedagogus, etc.).

A Deities text box comes next, which is designed to comprehend the names of the divinities mentioned in the inscriptions (lupiter Optimus Maximus, Junona, etc.).

Next is the Age textbox, in which the author records the number of years the individual lived for, in Roman numerals (L, IX, etc.). There where the age is unreadable due to the monument's state of conservation, the author must insert an interrogation mark (L[---]?, if the age is completely unreadable a question mark is to be inserted).

A Details of life/ death textbox follows and allows the author to insert a text with any relevant information (The inscription mentions the fact that he lived moderately, negotians splendid - sic!, etc.).

Then follows the Dedicated forl by check-boxes which record whether an inscription was dedicated by the specific individual or for him. When an inscription was elevated by an individual both for him and for someone else, then in the personal data sheet of the respective individual both check-in boxes (dedicated for, dedicated by) will be checked. An illustration of this is the example of Titus Aurelius Narcissus (ID 18) who made a dedication to lupiter Optimus Maximus and lunona Regina for him and his family, or that of Marcus Ulpius Longinus (ID 6904) who dedicated, while alive, a funerary inscription to his wife Ulpia Aquilinia (ID 6905), but also to himself.

In order for the personal data sheet to be connected to the encoded inscription, the author must fill in the search box with autocomplete or chose from a drop-down list the Inscription code he/she has attributed to the inscription which attests the individual whose data sheet is being recorded. Here multiple select is possible, in case of an individual attested without trace of a doubt by more inscriptions recorded in the database. The file cannot be saved without the inscription code being selected and thus the link made between the tables of the database.

Next follows an Ordo senatorius check-in box which if checked open two boxes, one which gives the author the possibility to record Details on the senator, and the other one which gives the possibility to record details on the Cursus honorum 
(curator viae Latinae, queastor urbanus, tribunus plebis, etc.). The Details field, here and for the following types of entries, is not compulsory to be filled in, it is only meant for the rare inscriptions which offer unstandardized (and impossibly to standardize) data on certain positions, occupations, realities in general. The Ordo equester check-in box follows and it is built on the same principles.

The check-in box Provincial governor is next, which if checked opens a box for Details (legatus Augusti propraetore, praeses Moesiae Inferioris, etc.), and two checkin boxes (Praetorian rank, Consular rank), one of which needs to be checked.

The Procurators check-in box follows, which if checked opens a procurator details box, and two check-in boxes (Praesidial and financial procurator).

The Local magistrate check-in box opens only a Details box, where the type and nature of the magistrature are to be filled in (president of the Assembly, Ilvir coloniae, etc.).

The Decurion check-in box opens a decurion Details box, as well as a dropdown list which allows to select the City/ town where the position was held, as well as a Multiple decurionate check-in box, which if checked opens itself a Details textbox, where the cities in which the multiple decurionate was carried on are to be recorded (Sarmizegetusa \& Apulum, etc.).

The Pontarch check-in box opens a Details textbox (here additional information

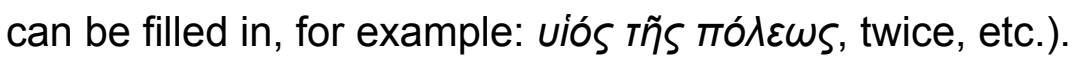

The Imperial slave and the Imperial freedman check-in boxes each open a Details textbox (dating, where there is the case).

The Military personnel check-in box opens a wider variety of options: first there is a military personnel Details textbox, followed by Military rank (decurio, vexillarius, etc.) and Military unit drop-down lists, as well as a Military career (tribuno legionis II Augustae, legato legionis $X$ Fretensis; secunda militia, etc.) textbox.

Following these a Decorations check-in box comes next, which opens a Details textbox (hastis faleris, corona murali; donatus torquibus, armillis, phaleris bello Dacico, etc.).

Lastly an Observations text area is available (a text area allows more than the 255 characters permitted by a text box) for the author to record any additional and useful information which has not been comprised in the above categories. Basically, this is the only category which is to include editorial comments, notes and other information that do not come directly from the source text, but are either deduced or historiographically known through the correlation of multiple sources. The Observations text area allows the author to use a higher number of characters than the textbox, which is limited. 
In the cases where there are in the inscription words which were incorrectly written by the lapicida, following the incorrect word the authors introduce "sic!" in order to draw attention to the mistake. For example, the individual under the ID number 162, Flavius Constantius appears as a custor templi, not a custos templi, as such, (sic!) appears after the mentioning of custor templi.

\section{Personal relations}

The last step is to create a relational linkage between those individuals whom are related to one another from various perspectives. As such, the author opens the Personal relations tab, and next the New relation between persons button (Fig. 5). After this, the user will be able to select from a drop-down list the name of the individual (the ID number appears next to it in order to make the identification more easy and certain), next from another drop-down list the Relation type is selected, and lastly from another drop-down list the person to whom the individual is connected. For each individual the relation is reciprocated, more precisely, if we have an inscription which attests a family relation of son and father, father and son, the author will have to record both types of relationships, meaning that it will have to create two separate records. One of the records will register the status of father of the specific individual (named as person 1) to the other individual (person 2), while the second record will register the status of son of the specific individual (now person 1, but previously recorded as person 2) to the other individual (now person 2, but previously recorded as person 1).

In the Observation text area, one can write different notes concerning the relation between the individuals, or any relevant data (E.g.: ID 3063 'lou 1 ía WifeOf ID 3064 Ф। $\lambda$ írkos. Text area: They were married for 38 years, and they had children; ID 3029 Aurelia Dusia MotherOf ID 3028 Aurelius Erculanus. Text area: She was his step mother; ID 3029 Aurelia Dusia WifeOf ID 3030 Seutes. Text area: She was his second wife). The text area is especially useful in those cases where there is an unspecified, or unreadable relationship type between the individuals, but the user may assume the

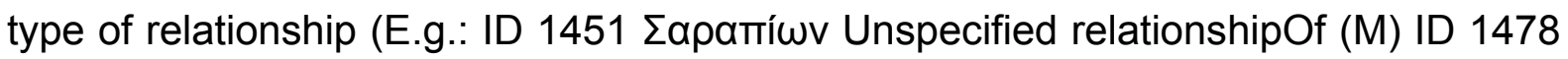

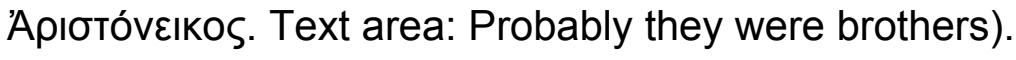

The Relationship types drop-down list comprises all relationships encountered in epigraphy, both familial and non-familial. The relationship types have been encoded, each receiving a specific three-digit code (Varga, "New Developments" 13-14). The first digit is 1-for first degree relationships, 2- second degree ones and so on up to 4- work/neighbourhood relations and 5- unknown/unspecified relations. The third digit 
stands for gender, as 1 is for male and 2 for female: e. g. 101 - Husband. The relationship types were designed to be as varied and encompassing as possible, this category being also further enriched when the authors came across a new type of relation in the inscriptions, through Relation table.

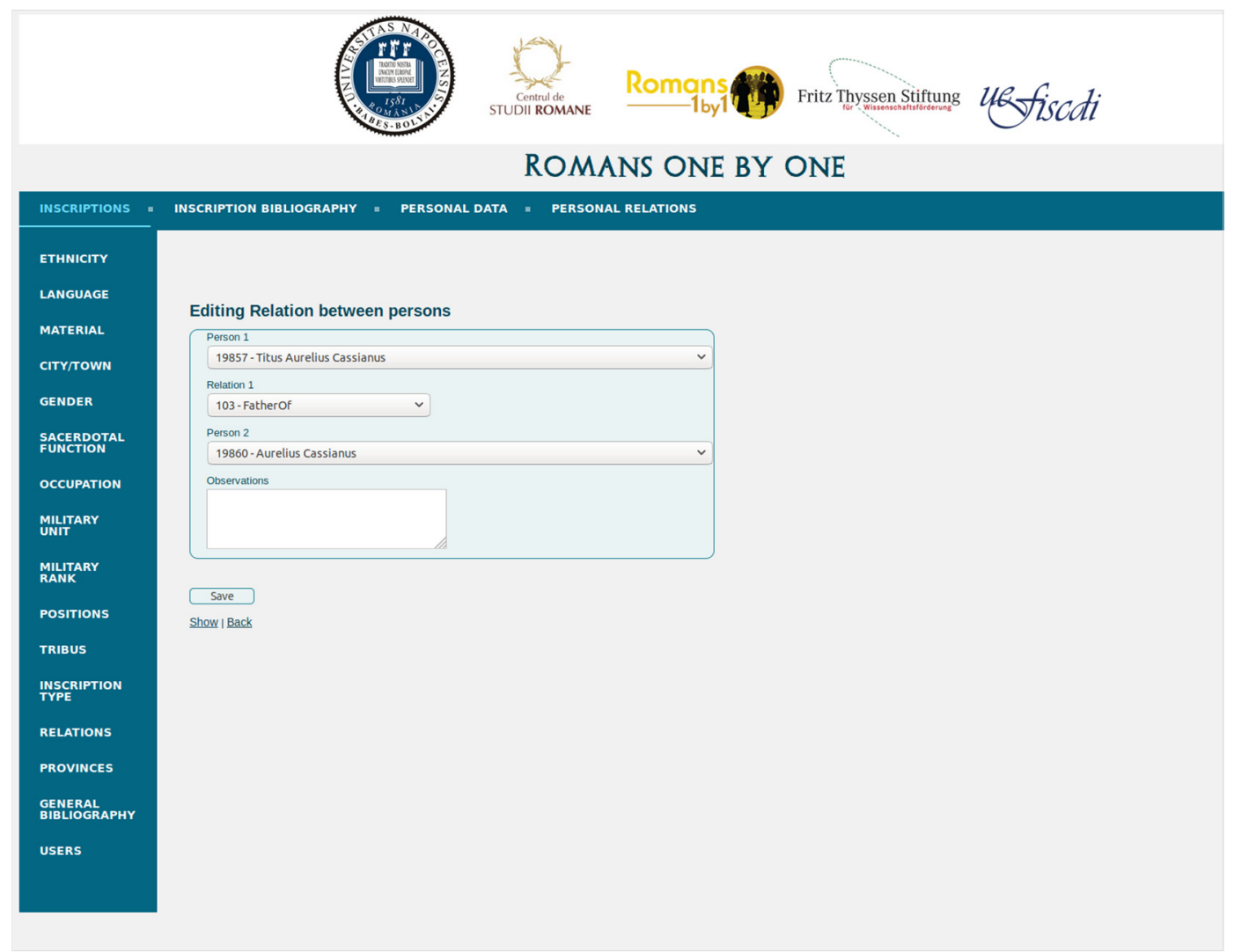

Fig. 5. New relation between persons file

Each record sheet can be later on edited or deleted by one of the users, action which is essential when working with a large data set.

\section{Left-side panel}

On the left side of the page, the account-based user can find the following tables: Ethnicity, Language, Material, City/ Town, Gender, Sacerdotal function, Occupation, Military unit, Military rank, Positions, Tribus, Inscription type, Relations, Provinces, and General bibliography. If individually clicked, all these tabs give the possibility to record new specific data, but editing them is possible only if one has an 
administrator account. For example, in case one of the authors comes across an inscription in Greek and the language cannot be found in the drop-down list, in order for him/ her to be able to select the language from the drop-down list, when creating a New inscription record, he/ she needs to first go to the left side of the panel, to the Language tab, press the New language record button and insert the language in the textbox and save the record. Similarly, if one of the authors comes across a new military unit which has not been attested in the previous inscriptions, an admin needs to go to the left side of the panel, to the Military unit tab, press the New unit record and introduce the name of the unit in the textbox, and save the record. By creating this new entry, the author will be able to select this information from a drop-down list on the "new person" field, connecting the unit to the name and the other identification details of an individual. Once the record is created for language it can be used every time the language appears in the new Inscriptions. The same rule applies for military unit, and all the other categories.

What is important is the fact that any new introduced data represents a new criterion of research. As such, in the case of a military unit, for example, one can do a prosopographical research which will provide all of the epigraphically attested individuals whom were part of a specific unit.

The open access database has six main tabs, some of which open sub-tabs, as follows:

\section{Home}

The home tab offers a brief synthesis on the database, as well as on the terms of use, and on the ways the user may offer their feedback.

\section{Team}

The team tab briefly presents the five researchers who worked in the building of the database, with further links to their CVs, lists of publications, and Academia webpage.

\section{About \\ Projects}

The project sub-tab offers information regarding the projects which helped and led to the development of the database.

\section{Conferences}

The conferences sub-tab directs the user to details regarding the conferences organised as part of the Romans1by1 projects. 


\section{Educational Initiatives}

The educational initiatives sub-tab provides information on workshops, seminars, etc.

\section{Contact}

Next, the contact sub-tab, offers the opportunity to the users to contact the database administrator.

\section{People}

The two most important tabs are the forth and the fifth ones, which allow the user to browse, research and filter the data, as well as download it (Excel download). The existing search filters for this tab are prosopographically oriented, as such we have the possibility to search the name of an individual, the province and/ or place of origin, the corresponding bibliography, but we can also make a general search based on key words. This table offers the possibility of simple searches, based on Name, Province, Place, Bibliography and a text-based General search (Fig. 6; Fig. 7; Fig. 8).

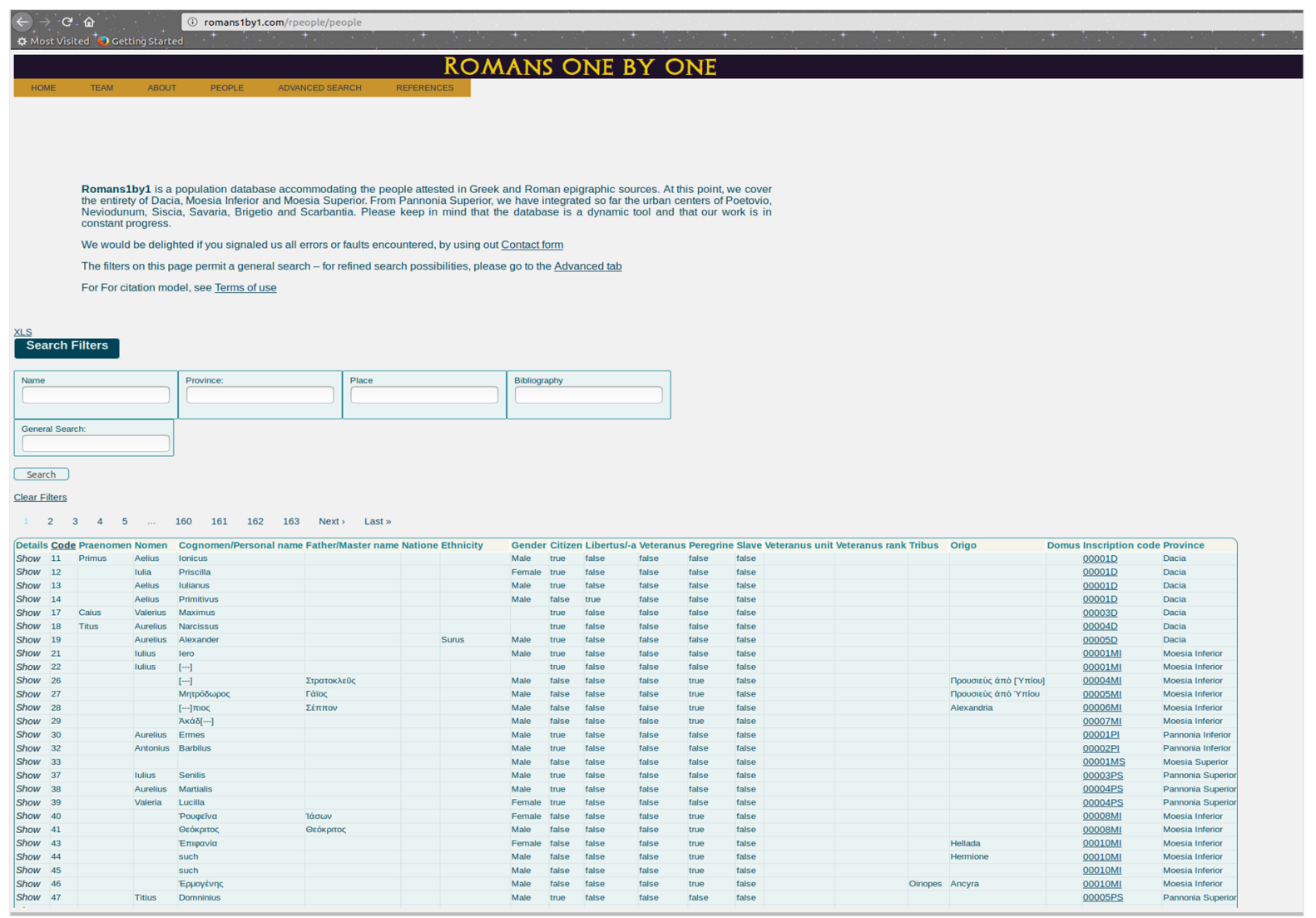

Fig. 6. Interface of the open access version 


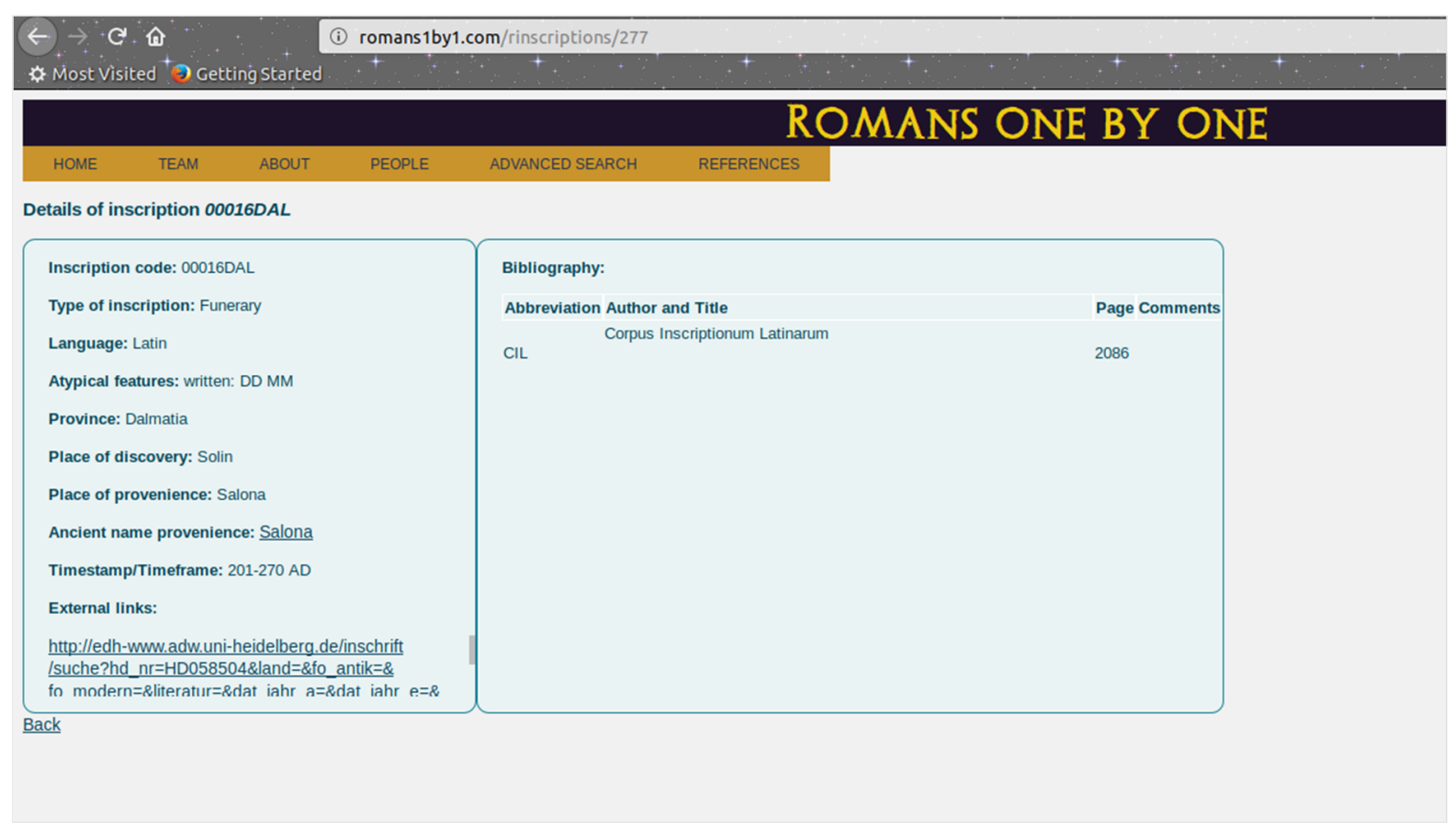

Fig. 7. Example of inscription file (open access)

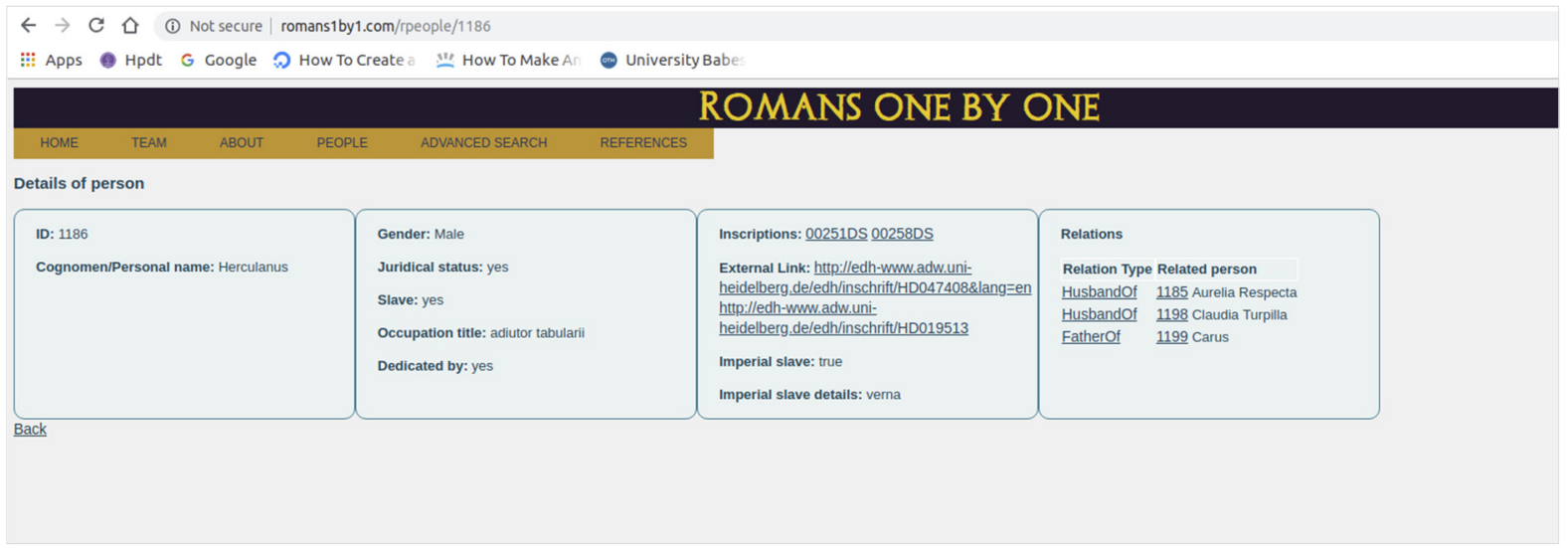

Fig. 8. Example of person file (open access)

\section{Advanced Search}

The advanced search is an extended version of the previous one, this one including a large variety of research filters which allow the user to select specific ones (Fig. 9). As all the databases which are built on research filters, the usefulness of it is given by the fact that it offers to the user a greater precision and swiftness in retrieving 
the needed information. Moreover, various prosopographical filters can be combined, which gives a great flexibility to the user who, based on the specific interest he/ she has at a certain moment, can narrow down the information and the sources. The existing research filters match with the data categories presented in the personal data sheet paragraph.

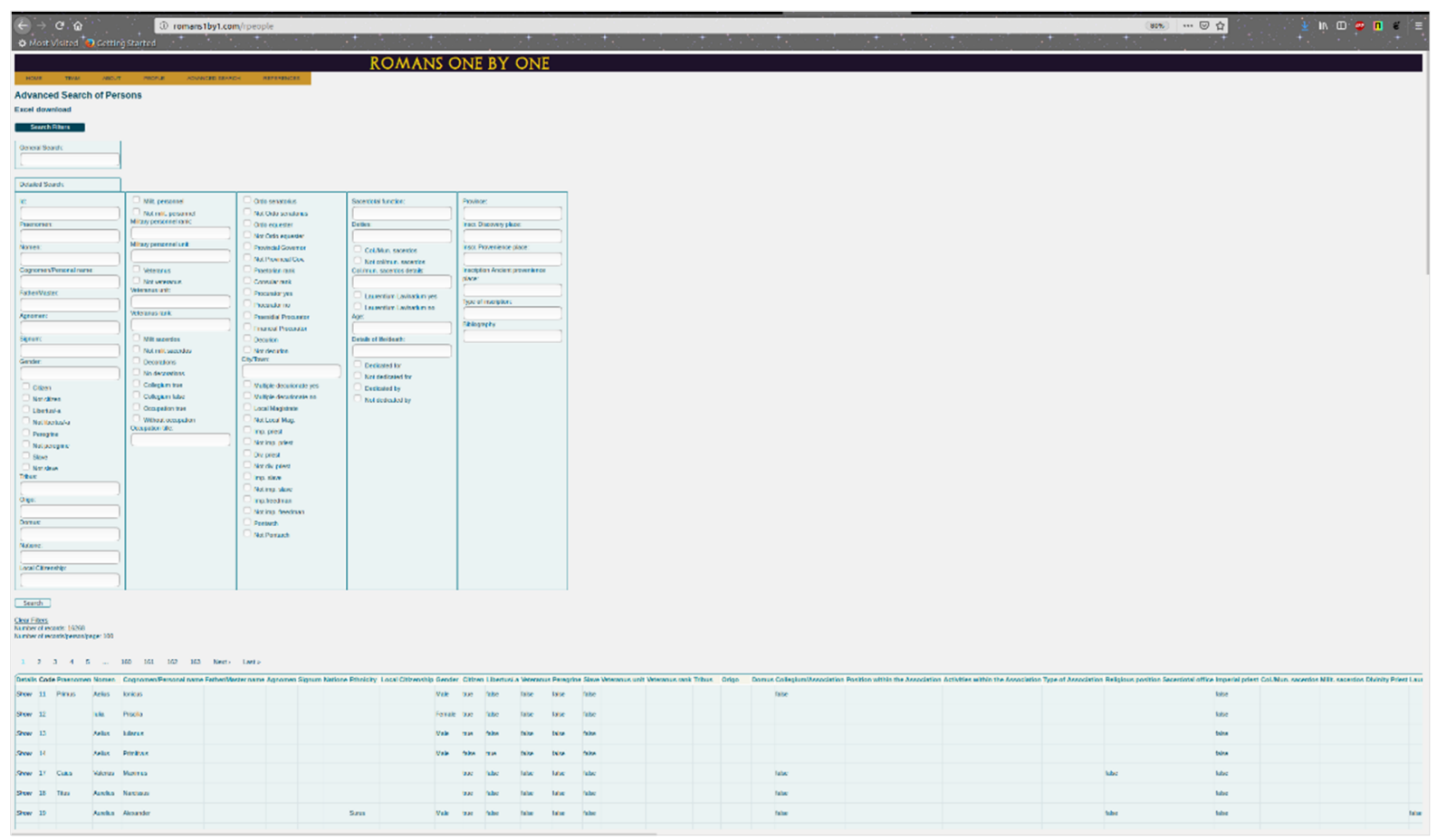

Fig. 9. Advanced menu on the open access website

\section{References}

\section{Abbreviations and Bibliography}

In the abbreviations and bibliography tab, the user can retrieve the corresponding abbreviations of the bibliographical works we used (Fig. 10). The abbreviations follow mostly the principles of the Année Philologique. In this section one can also make a search based on a specific abbreviation, or on a title of a publication.

\section{Database Documentation}

This section comprises a link to the publications which document various aspects related to the database, from the applied methodology, to its architecture, and to its overall informational content and contribution. Besides the publications, one can 
also find links to the presentations given by some of the team members regarding the database at various events.

\section{Scientific Publications}

The last sub-tab encompasses a list of publications which examine specific prosopographic or demographic aspects, the primary data on which the topic was built being downloaded from the database.

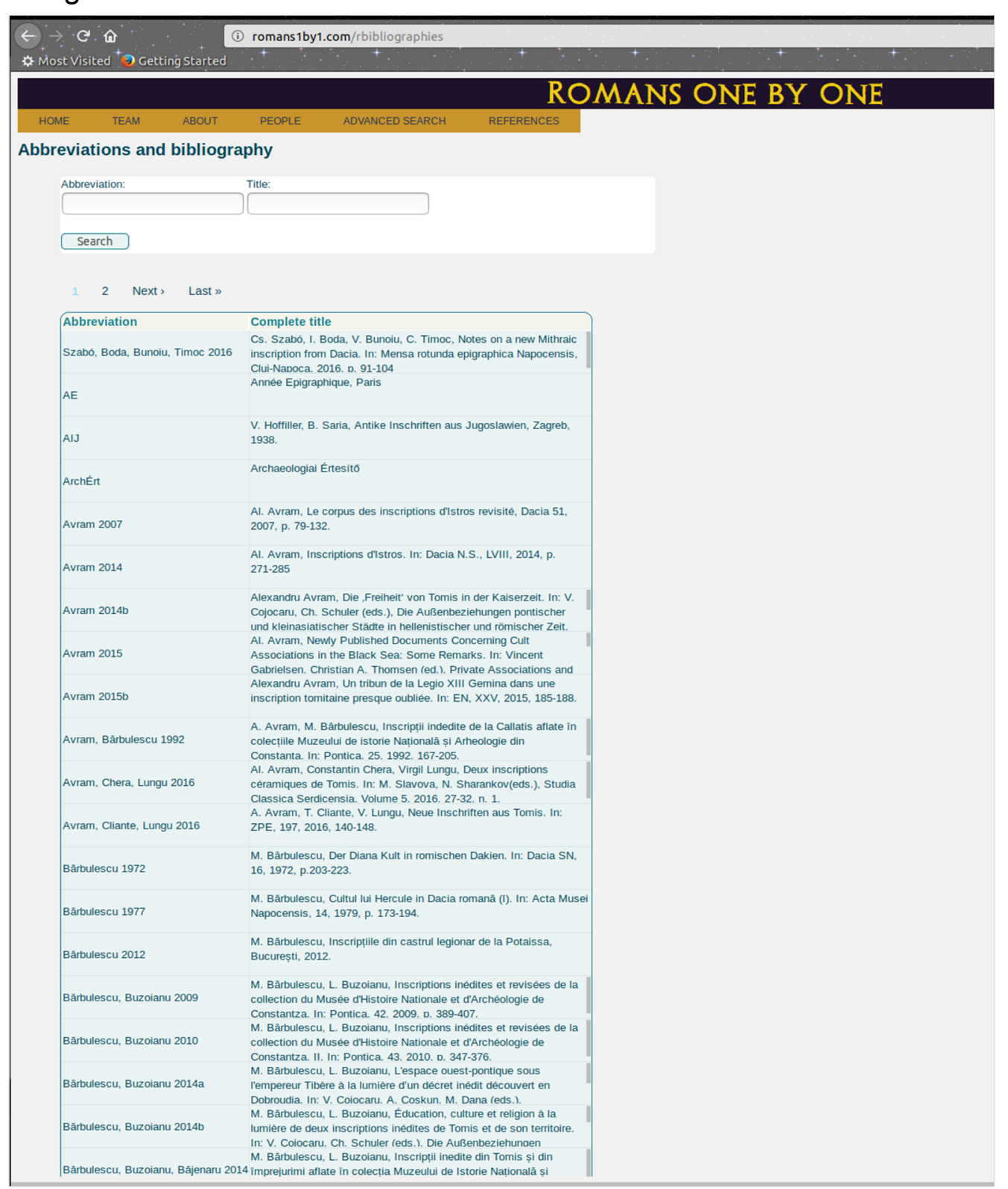

Fig. 10. Bibliography list on the open access website 


\section{Differences between the two platforms}

The differences between the two platforms consist in the changes and data input which can be done in the first one, in comparison with the second, as well as in the pure exploratory and browsing character of the second.

The database is dedicated not only to the specialists in the field whom use it for research purposes, but also to the wider public, be it individuals passionate about ancient history, or school teachers who can use the database as a pedagogic tool. Certainly, from an external point of view, the advantage of the database is the fact that it is in English, which ensures a wider access to it.

\section{Acknowledgement}

This work was supported by a grant of the Ministry of Research and Innovation, CNCS - UEFISCDI, project number PN-III-P4-ID-PCE2016-0255, within PNCDI III.

\section{Works Cited}

Becker, Sascha O., Francesco Cinnirella, Erik Hornung, Ludger Woessmann. "iPEHD - The ifo Prussian Economic History Database." Historical Methods: A Journal of Quantitative and Interdisciplinary History, vol. 47, no. 2, 2014, pp. 57-66.

Carrion, Daniela, Federica Migliaccio, Guido Minini, Cynthia Zambrano. "From Historical Documents to GIS: A Spatial Database for Medieval Fiscal Data in Southern Italy." Historical Methods: A Journal of Quantitative and Interdisciplinary History, vol. 49, no. 1, 2016, pp. 1-10.

Cook, Lisa D. "Converging to a National Lynching Database. Recent Developments and the Way Forward." Database Developments. Historical Methods, vol. 45, no. 2, 2012, pp. 5563.

Dormans, Stefan, and Jan Kok. "An Alternative Approach to Large Historical Databases." Historical Methods: A Journal of Quantitative and Interdisciplinary History, vol. 43, no. 3, 2010, pp. 97-107.

Hedefalk, Finn, Lars Harrie, and Patrick Svensson. "Methods to Create a Longitudinal Integrated Demographic and Geographic Database on the Micro-Level." Historical Methods: A Journal of Quantitative and Interdisciplinary History, vol. 48, no. 3, 2015, pp. 153-173. 
Huistra, Hieke, and Bram Mellink. "Phrasing History: Selecting Sources in Digital Repositories." Historical Methods: A Journal of Quantitative and Interdisciplinary History, vol. 49, no. 4, 2016, pp. 220-229.

Kennedy, Gregory and Kris Inwood. "A New Prosopography. The Enumerators of the 1891 Census in Ontario." Database Developments. Historical Methods, vol. 45, no. 2, 2012, pp. 65-77.

Mandemakers, Kees and Lisa Dillon, "Best Practices with Large Database on Historical Populations." Historical Methods: A Journal of Quantitative and Interdisciplinary History, vol. 37, no. 1, 2004, pp. 34-38.

Massey, Catherine G. "Playing with Matches: An Assessment of Accuracy in Linked Historical Data." Historical Methods: A Journal of Quantitative and Interdisciplinary History, 2017, pp. 1-15.

Murmann, Johann Peter. "Constructing Relational Databases to Study Life Histories on Your PC or Mac." Historical Methods: A Journal of Quantitative and Interdisciplinary History, vol. 43, no. 3, 2010, pp. 109-123.

Noble, Petra, David Van Riper, Steven Ruggles, Jonathan Schroeder and Monty Hindman. "Harmonizing Disparate Data Across Time and Place: The Integrated Spatio-Temporal Aggregate Data Series." Historical Methods: A Journal of Quantitative and Interdisciplinary History, vol. 44, no. 2, 2011, pp. 79-85.

Varga, Rada. "Romans 1 by 1 v. 1.1. New Developments in the Study of Roman Population." Digital Classics Online, vol. 3, no. 2, 2017, pp. 44-59.

Varga, Rada. "Romans 1 by 1 . Documenting a Population Database for the Roman World." Digital and Traditional Epigraphy in Context. Proceedings of the EAGLE 2016 International Conference, edited by S. Orlandi, R. Santucci, F. Mambrini, P.M. Liuzzo, Sapienza Università Editrice, 2017, pp. 333-341.

Varga, Rada, "The Professionals of the Latin West." Social Interaction and Status Markers in the Roman World, edited by R. Varga, G. Cupcea, Archaeopress, 2018, pp. 9-22.

Varga, Rada, Annamária-I. Pázsint, Imola Boda, and Dan Deac. "Romans 1 by 1: Overview of a Research Project." Digital Classics Online, vol. 4, no. 2, 2018, pp. 37-63.

Varga, Rada, and Angela Lumezeanu. "The Process of Record Linkage on Roman Epigraphical Sources." Historical Methods: A Journal of Quantitative and Interdisciplinary History, 2019, in print. 